EJMBE

30,1

36

Received 29 March 2019

Revised 10 December 2019 28 March 2020

Accepted 8 April 2020

\section{Is it my fault and how will I react? A phenomenology of perceived causes and consequences of workplace ostracism}

\author{
Ahmad Raza Bilal \\ Faculty of Business, Sohar University, Sohar, Oman \\ Tehreem Fatima \\ Lahore Business School, The University of Lahore, (Sargodha Campus), \\ Lahore, Pakistan \\ Muhammad Kashif Imran \\ School of Business Management and Administrative Sciences, \\ The Islamia Univeristy of Bahawalpur, Bahawalpur, Pakistan, and \\ Kamran Iqbal \\ Department of Business Studies, Bahria University, Islamabad, Pakistan
}

\begin{abstract}
Purpose - This exploratory inquiry sheds light on the nature of victim (i.e. provocative and passive) and specific work context in shaping the perceived causes and outcomes of felt workplace ostracism in teaching faculty of Pakistani higher educational institutions (HEIs) based on target-centric victimization framework.

Design/methodology/approach - This phenomenological research is based on data gathered from 30 ostracized teaching faculty members working in Pakistani public and private HEIs through in-depth semistructured interviews. The interviews were tape-recorded, and transcription was entered in NVivo 12 Plus software to conduct thematic analysis.

Findings - This study found that provocative and submissive victim status, as well as the specific contextual factors in Pakistani HEIs (i.e. negative competition, cronyism, egoism and poor interpersonal relationships), is responsible for fostering workplace ostracism and yielding unique outcomes in each case.

Originality/value - This study has taken the scantly used target-centric victimization framework to distinguish the causes and consequences of workplace ostracism based on the nature of victim and work context in Pakistani HEIs .
\end{abstract}

Keywords Higher educational institutions, Workplace ostracism, Provocative victims, Submissive victims, Victimization framework

Paper type Research paper

\section{Introduction}

Workplace ostracism is being excluded, ignored or omitted from the social interactions within organizational settings (Howard et al., 2019). The extant research on workplace ostracism has signaled mixed findings regarding its positive, negative and avoidant outcomes (Robinson et al., 2013). How an ostracized employee reacts is considerably dependent on a multitude of

(C) Ahmad Raza Bilal, Tehreem Fatima, Muhammad Kashif Imran and Kamran Iqbal. Published in European Journal of Management and Business Economics. Published by Emerald Publishing Limited. This article is published under the Creative Commons Attribution (CC BY 4.0) licence. Anyone may reproduce, distribute, translate and create derivative works of this article (for both commercial and noncommercial purposes), subject to full attribution to the original publication and authors. The full terms of this licence may be seen at http://creativecommons.org/licences/by/4.0/legalcode
European Journal of Management and Business Economics Vol. 30 No. 1,2021 pp. $36-54$

Emerald Publishing Limited e-ISSN: 2444-8494

p-ISSN: $2444-8451$

DOI 10.1108/EJMBE-03-2019-0056 
factors (Richman and Leary, 2009). From a theoretical perspective, workplace ostracism research usually employed "Temporal Need Threat Model" (Williams, 2009), emphasizing the time- and need-based aspects, or used "The Multimotive Model of Responses to Social Rejection" (Richman and Leary, 2009) that focused on construal factors impacting the outcomes of being socially rejected. Recent directions suggest that the nature of the victim (Aquino and Lamertz, 2004; Howard et al., 2019) and work context (Mao et al., 2018) also play a decisive role in this regard. We build on the target-centric victimization framework presented by Aquino and Lamertz (2004), which is useful to comprehend the causes and outcomes of any form of victimization. Victims are termed as those individuals who perceive themselves as recipients of any harmful behavior by another party. In this realm, two types of victims exist: provocative and submissive; the former relates to individuals who respond aggressively, and the latter signal self-abasement (Aquino and Thau, 2009). Workplace ostracism elicits either prosocial, socially avoidant or antisocial outcomes (Richman and Leary, 2009; Robinson et al., 2013). The past research has examined some of the workplace mistreatments from the target-centric victimization perspective, such as workplace bullying (Matthiesen and Einarsen, 2015) and workplace aggression (Ren et al., 2018). Until now, scant attention is given to victim and context-focused viewpoint in examining the antecedents and outcomes of workplace ostracism that only build on conceptual arguments (Howard et al., 2019).

Workplace ostracism is pervasive in all kinds of business, cultural and national contexts, but some of them are more vulnerable in this regard. Higher educational institutes (HEIs) have organizational dynamics where inclusiveness, interpersonal ties and norms of collaboration are highly valued (Bashir and Khalil, 2017), and their absence yields detrimental outcomes (Nasir et al., 2017). Recent research has highlighted the importance of examining ostracism in specific academic settings and called for further exploration in this regard (Bilal et al., 2019; Nasir et al., 2017;Zimmerman et al., 2016). Most conceptual studies on workplace ostracism recognize the role of work context in explaining the outcomes of ostracism (Robinson et al., 2013; Scott and Duffy, 2015; Williams, 2007), yet this stance is not substantially tested. Workplace ostracism reactions may have different causes and consequences depending on context (Jahanzeb and Fatima, 2018). From this perspective, HEIs in collectivist and developing nations are increasingly witnessing a higher rate of ostracism (Fatima et al., 2017) and a unique tendency toward work behaviors after being ostracized (Bilal et al., 2019; Robinson et al., 2013).

These factors require a rethinking of the over-simplistic conclusions drawn about the causes and consequences of workplace ostracism and generalizing them across all kinds of business settings. Workplace ostracism has unique implications concerning victims' nature and cultural dynamics, so understating this phenomenon through the lived experiences of participants is a convincing approach (Polit and Beck, 2004). Qualitative research provides a plausible imperative in offering valuable insights into workplace ostracism (Waldeck et al., 2015; Waldeck, 2017) to disentangle the understanding of varied responses (Bilal et al., 2019) based on unique work context and nature of victims.

This study explores the unique causes and outcomes of workplace ostracism in HEIs and highlights the differences based on the distinct nature of victims and academic work settings. In this research, we have limited the focus to felt ostracism experienced by the teaching faculty of HEIs in a collectivist and developing nation of Pakistan. Firstly we attempted to answer "how teaching faculty in HEIs perceives the causes of felt ostracism according to their nature i.e. provocative or submissive, and how this perception shapes their work outcomes?" Secondly, we probe "how the work context i.e. culture, working relationships, norms, etc. of HEIs develops a perception of felt ostracism in teaching faculty and influence their work outcomes?" By answering these questions, this study contributes to the extant literature by opting for an exploratory qualitative stance that takes into account the role of victims' nature
Causes and consequences of workplace ostracism 
EJMBE 30,1

and work contexts in revealing the causes and outcomes of workplace ostracism in HEIs based on target-centric victimization perspective.

\section{Theoretical framing}

The target-centric victimization framework proposed by Aquino and Lamertz (2004) suggests that victims' associated characteristics and behaviors constitute one of the factors that can be used to discern the antecedents and outcomes of mistreatment. Howard et al. (2019) advocated the usefulness of this theoretical perspective in examining the concept of workplace ostracism. In this regard, the nature of the victim as well as specific factors in the work context shapes how an individual attributes the causes of ostracism and how it impacts his/her outcomes. In this study, we have taken the victim- and context-focused stance to examine the causes and outcomes of workplace ostracism in the specific context of Pakistani HEIs.

\subsection{Causes and consequences of workplace ostracism based on nature of victims and work context}

Aquino and Lamertz (2004) differentiate the two categories of victims that exhibit dissimilar characteristics: provocative victims and submissive victims. According to Aquino and Lamertz (2004), submissive victims are "extremely passive, insecure, frequently rejected by peers, and unwilling to defend against attack" (p. 1025). These people face insulting and offensive treatment because of their low social profile and support, as suggested by behavioral decision-making theories. Individuals consider cost and benefits attached to their behaviors and perform those activities that are beneficial in terms of cost-benefit analysis, and this cost-benefit analysis helps them to choose from among the available alternatives (Tepper et al., 2006). Submissive victims show minimal retaliation after being mistreated. Therefore, perpetrators find such individuals an easy target of ostracism because they have to face minimal adverse consequences.

On the other hand, provocative victims are very irritating, hostile and aggressive. Their actions compelled others to retaliate against them, which has been explained through norm theories (Aquino and Lamertz, 2004). Social normal is defined as standard behaviors that are desired from the group's members, and these norms should be considered as important by group members for the smooth functioning of a group. Because of this perceived importance, group members will try to reinforce these norms in the group through penalties and rewards. This viewpoint suggests that workplace ostracism is initiated as punishment against group members who violate these norms, and ostracism is an outcome of these violations (Hitlan and Noel, 2009; Robinson et al., 2013). Retaliatory ostracism could be the result of deviant norm violations to "keep people in line," but it may also a reaction to nondeviant norm violations. The ostracizing behaviors could also be deployed to discourage undesirable behavior, for instance, ostracizing a poorly performing individual. Although it could be possible that individuals may be exhibiting poor performance unintentionally, other group members ostracize these poor performers to enhance overall group performance or perceive that employee performance is intentionally poor for instance social loafing (Wu et al., 2019; Williams and Sommer, 1997).

At one fell swoop, working conditions state the risks and returns of ostracizing others. Similarly, the work environment has inherent features to support (discourage) ostracism due to the attached risks and returns, which could be high or low on either side. Furthermore, environmental factors are recognized as an important trigger to explain the intensity of ostracism. Predominantly, social environmental perceptions and leadership are sources to establish such norms. This way, perception to understand these behaviors as normative is the 
result of contained unfavorable workplace conditions (Hitlan and Noel, 2009; Robinson et al., 2013). Further, several arguments explained the instances where ostracism generates normative behaviors, but there are some clues from existing research that it becomes the by-product of the mild environment. In innocuous environments, employees may receive high returns as compared to risks in response to ostracism. Contrary to this, certain work environments permit employees to do ostracism-related activities because of surface-level features (gender, race) that deviated from existing norms. In doing so, such an environment produces high risk as there is a very minute cost of ostracism like lack of punishments (Leung et al., 2011; Ng, 2017). There are different motivations of ostracism when applied conditions are different, like employees use ostracism tools to "get ahead" in competitive work environments as compared to a cooperative work environment where employees prefer to reduce workplace ostracism (Halevy et al., 2014). In the former environment, employees perceived to get returns of "pushing out" others by way of offsetting the risk of social resource, whereas in later workplace conditions, employees pay due attention to social inclusiveness (Robinson et al., 2013). The climates of self-interest and favoritism on the non-merit basis are also linked with increased instances of workplace ostracism (Bilal et al., 2019). Moreover, certain workplaces lack coherent relationships among colleagues and create "chilly" climates that have been linked to workplace ostracism in the past (Zimmerman et al., 2016).

Workplace ostracism is caused due to diverse factors, and it cannot be generalized in all work environments and for all kinds of victims. Building on the victimization framework, we argue that victim characteristics and specific work environments play a key role in explaining the cause of felt ostracism.

$P 1$. The antecedents of workplace ostracism will be different for provocative and submissive victims.

P2. The antecedents of workplace ostracism will be different for the unique context of HEIs in Pakistan.

Most of the reported outcomes of workplace ostracism are negative (Robinson et al., 2013), whereas some evidence of positive outcomes has also been traced (Scott and Duffy, 2015; Xu et al., 2017). It has been indicated by extant studies that submissive victims refrain from showing overt reactions as a response to mistreatment, and they mostly avoid confrontation in this matter. The provocative victims engage in a more overt form of reactions that are more negative and hostile (Ng, 2017). Whether victim of ostracism will improve work outcome, withdraw or reduce work outcome is decided by the nature of the victim as well as the environmental context of the workplace (Howard et al., 2019).

P3. The outcomes of workplace ostracism will be different for provocative and submissive victims.

P4. The outcomes of workplace ostracism will be different for the unique context of HEIs in Pakistan.

\section{Method}

\subsection{Research design}

The perceived causes and personal experiences of victims are the prime factors in deciding the outcomes of workplace ostracism rather than its actual occurrence. That is why a phenomenological inquiry that enables to "understand several individual's common or shared experiences of a phenomenon" (Creswell, 2007, p. 60) and elicits a deeper understanding of lived experiences of participants was deemed a suitable and recommended approach in this regard (Waldeck, 2017). 
EJMBE 30,1

\subsection{Population and sampling}

The population consists of teaching faculty of Pakistani (public and private) universities. We purposefully chose the participants who had experienced a considerable degree of workplace ostracism, as they were well-equipped to answer the research questions. To attain this, the authors developed qualifying criteria based on existing workplace ostracism conceptualization (Ferris et al., 2008) that has been used in ostracism research in a similar context (Bilal et al., 2019), that is, "Do you constantly feel excluded or ignored in formal and informal social interactions in your department?" "Is your opinion seldom/never invited in formal and informal matters?" "Do you see yourself as not being a member of dominant in-group in your department?" "Do you constantly feel out of the loop"? The authors used personal links to forward this information to faculty groups of public sectors and private universities in Lahore along with a short description of the purpose of this research. A total of 47 individuals responded and were found to fulfill the criteria; out of them, 36 participants volunteered to participate in the study. Interviews were carried out in person with each of the participants at a mutually agreed-upon venue; after completion of 27 th interview, the researcher felt that repetition of data started occurring that met saturation criteria (Saunders et al., 2018). For further assurance, three more interviews were carried out that indicated sufficient data were obtained regarding research propositions and no new theme emerged (Jassim and Whitford, 2014). The sample size of 30 was deemed sufficient, as participants ranging from 10 to 30 are appropriate in the phenomenological approach (Bilal et al., 2019; Hall et al., 2016; Yang, 2008).

\subsection{Data collection}

To collect data, a semi-structured interview guide was prepared based on existing research about the causes and consequences of workplace ostracism (Howard et al., 2019; Mao et al., 2018; Robinson et al., 2013). To authenticate the interview guide, a panel of four experts was formed; it had two academicians and two experts of qualitative research who reviewed it and suggested some amendments that were duly incorporated. In the first step, the participants were briefed about the research topic, and, in the second step, they were requested to respond related to workplace ostracism. One of the sample interview questions is: "What do you think initiated ostracism?"; the prompts were (Which cause do you attribute to the occurrence of ostracism? Do you feel it is your fault or that of the perpetrator? Why you were the target?). The interviews spanned from $35-55 \mathrm{~min}$, which is quite acceptable according to the average time of $40.7 \mathrm{~min}$ in phenomenological inquiries (Follmer et al., 2018).

\subsection{Data analysis}

The interviews were recorded with the consent of participants, and transcription was done after that. To analyze the data, thematic analysis was deemed a suitable choice (Braun and Clarke, 2006). The transcribed interviews were imported in NVivo 12 plus, and each participant was treated as a case. It is suitable software for the development of codes and subsequent themes as it aids in efficient qualitative data analysis (Banihani and Syed, 2017). The transcripts were thoroughly read to gain familiarization, and the emerging initial codes were developed. Codes that exhibited similar patterns were categorized under preliminary themes. These themes were reviewed (repetition and extra information were eliminated) and revised to ensure that they represented answers to the research questions. A matrix coding query option was used to determine the frequency of each theme, and their percentages were calculated.

\subsection{Reliability and validity}

To establish reliability, inter-coder agreement was used (Silverman, 2005). Two independent coders reviewed data and developed codes and themes that were matched with those 
developed by authors. Few differences were traced that were adjusted to through discussion to generate a list of agreed-upon themes. Member validation was used during the interview process as well as after the analysis (Silverman, 2005; Sarma, 2015). The transcriptions were sent back to the respective interviewees to make sure that they represented what they intended to state. Moreover, after the completion of themes, development and interpretation, their summary was shared with the participants and their affirmation was sought that the results are the reflection of participants' views, feelings and experiences. The feedback of participants was used in improving the data interpretation and in removing any misleading information.

\section{Results}

\subsection{Demographics}

Out of the 30 participants, 17 were male and 13 were female; their age ranged from 26 years to 45 years; from the total sample, 19 were married and 11 were single. The designation showed a mixed profile: 14 were lecturers, 9 were assistant professors and 7 were associate professors. With regard to education, 21 had MPhil degree, while 9 were $\mathrm{PhDs}$. All participants belonged to both public (18) and private (12) sectors. Out of the 30 participants, 18 were from the submissive category and 12 were from the provocative category.

\subsection{Thematic analysis}

From the analysis of data, two major themes emerged that were related to the perception of faculty's causes and outcomes of ostracism in HEIs. The theme of perceived causes was bifurcated based on provocative victims and submissive victims, and then according to the contextual factors. A similar stance was taken in developing sub-themes of consequences of workplace ostracism. The relative frequencies and percentages of each theme are presented in Tables 1 and 2.

\subsection{Perceived causes of workplace ostracism for teaching faculty of HEIs}

This theme was further sub-divided in the following sub-themes.

4.3.1 Perceived causes of workplace ostracism for provocative victims. Most of the provocative victims indicated constructive deviance, cronyism and envy as the causes of being ostracized. The first cause of felt ostracism was attributed to the personal actions of victims. It was reported by the provocative victims that they usually go against the status quo to improve work practices in the department, complain against inefficient colleagues, disagreed with colleagues that followed redundant work procedures or bent rules and regulations for the satisfaction of students and improvement in the department. In the view of participants, these actions lead them to be ostracized in general, and sometimes specifically by those whom they disagreed with. It was explained by one faculty member as:

I believe in the improvement of work output, even if it is attained by going against any norm or rule that has been in practice for years. What is wrong should be reported and initiatives should be taken to improve it but sadly what I received is isolation from my colleagues (P\#11).

A second important cause of ostracism perceived by provocative victims was the envy of colleagues and department heads. It was highlighted by victims that they have good academic credentials, student feedback and a research profile that spur insecurity and negative emotions among the colleagues that do not possess these qualities. Ostracizing is a subtle outlet for the colleagues' expression of their negative emotions they feel after unfavorable social comparison. It was reported by one faculty member:

I am good at research and I often get funding for foreign conferences . . .I am very passionate about guiding my research students and they show quality work output. This has mainly attracted 
EJMBE

30,1

42

\section{Table 1.}

Matrix coding query results of perceived causes of workplace ostracism*

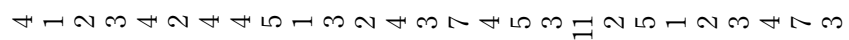

o on

N + t m

กุ่

Fำช

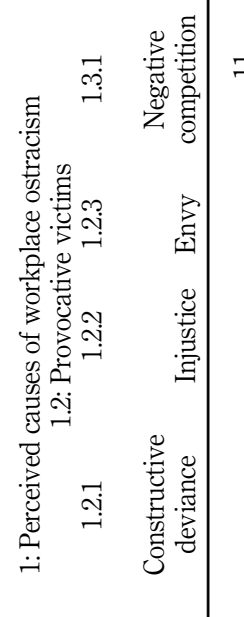

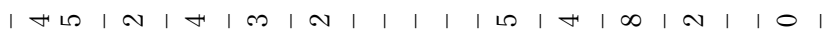

|

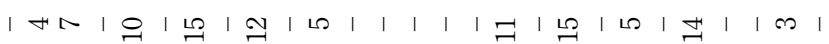

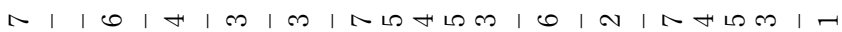
正兽:

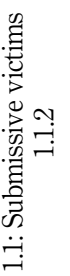

过.

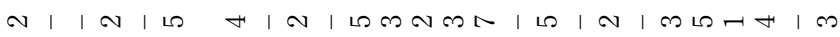

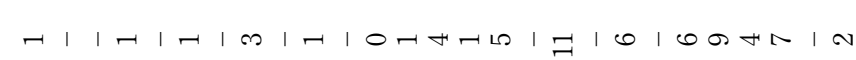

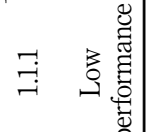




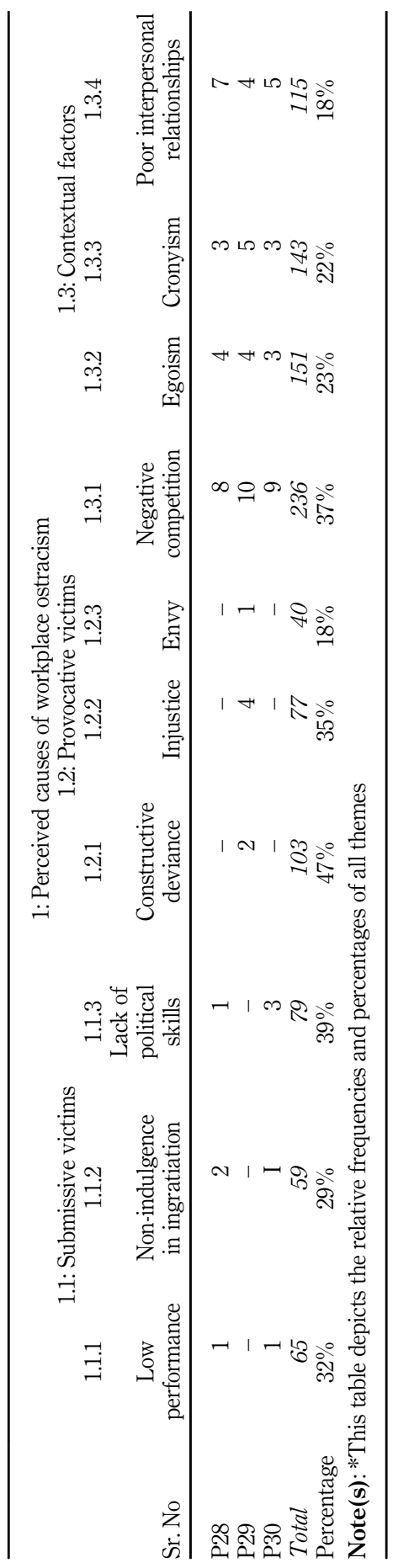

Causes and consequences of workplace ostracism

43

Table 1. 
EJMBE

30,1

44

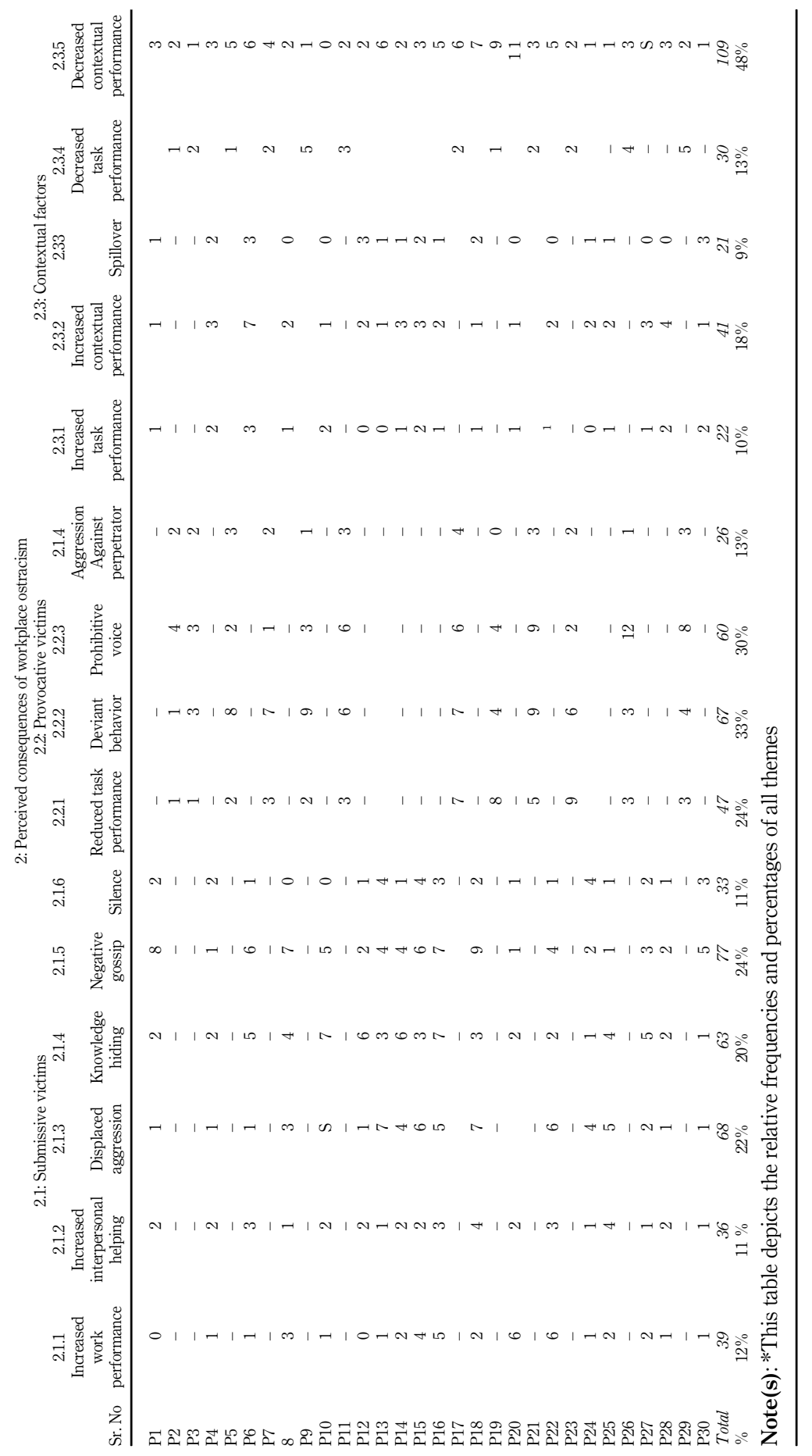

Table 2.

Matrix coding query results of perceived consequences of workplace ostracism* 
negative behavior from my colleagues ... I feel that they do not like to involve me in their in-formal gatherings and avoid interaction with me (P\#17).

Another participant shed light on more formal ostracism:

Outperformers receive a social cost in our department, I often experience that only average performers thrive here ... I have a foreign Ph.D. degree and I am usually sidelined in many instances, my opinion and suggestions are not asked or even if I give them my colleagues and Head pay a deaf ear to them $(\mathrm{P} \# 29)$.

4.3.2 Perceived causes of workplace ostracism for submissive victims. Submissive victims perceived ostracism because of their low performance, lack of political skills, non-indulgence in ingratiation and high cronyism.

Submissive victims mostly attributed their characteristics to be the cause of ostracism. They believe that they perform lower than other colleagues, and due to their inefficient working, their peers avoid them in work teams, in social interactions and in seeking advice and suggestions regarding important departmental matters. It was revealed by one faculty member:

I think that my performance is not up to mark whereas my colleagues are more punctual, passionate, and efficient in completing their assigned tasks. My head often snubs me because my work is never error-free. Mostly my image of being a work shirker or underdog makes me feel left out in interpersonal situations $(\mathrm{P} \# 4)$.

The second personal characteristic reported by submissive victims was their poor political skills. The ostracized faculty members in this category stated that they had difficulty in developing social relationships and were not clever enough to appropriately behave in diverse social interactions. It was the opinion of participants that they were not very desirable socially given their deficient convincing skills. A faculty member said:

I am only good at teaching and doing my assigned job duties, but I lack the personal ability to deal with the political situations facing in our educational settings. It is very tough for me to develop relationships with colleagues and be a part of certain groups to display socially desirable attitudes. I occupy a comparatively lower social standing in my department and it makes me face cold and noninclusive behavior from my peers $(\mathrm{P} \# 12)$.

Another similar concept emerged in this context, where victims also indicated that they were unable to spend extra efforts for making their heads and colleagues happy, that is, they do not indulge in flattery, servility and giving extra favors to peers, so they were not liked and included by them. One respondent stated:

Here is a culture of flattery and going the extra mile to keep everyone happy and I do not indulge in such behavior. I think as professionals we only owe the services to organizations and nothing more than that ... But somehow, it has cost me the social inclusion in my department (P\#25).

4.3.3 Perceived causes of workplace ostracism within the specific context of HEIs. Although perceived causes of workplace ostracism are elaborated as per the victim characteristics, some of the contextual factors that impacted both types are linked to the specific work context of HEIs in Pakistan, such as competitive environment, egoism and poor interpersonal relationships based on cronyism.

In general, the respondents agreed to the point that HEIs have now fewer resources, and everyone has to compete for resources and survival of their jobs. This competition is profoundly negative, and everyone wants to win even at the cost of harming colleagues, departments and organizations. This has promoted a competitive and egoistic climate where everyone is out for themselves, and inclusiveness and cooperation are now extinct. Moreover, the relationships between the department head and colleagues as well as among colleagues
Causes and consequences of workplace ostracism 
EJMBE 30,1

are not closely knit, and very few conscious efforts are made to improve this situation. It was stated by one faculty member,

In HEIs, there is a race for survival ...inclusion and exclusion dynamics are based on self-interest (P\#4).

In our department, all faculty members have minimum social interaction and there is no mechanism to improve the relationship among colleagues on a departmental or individual level ( $\mathrm{p} \# 9$ ).

The relationships based on personal associations were deemed as a reason for feeling ostracized, as only favored group members of department heads were included in the majority of department affairs. Particularly, the submissive victims were not a part of any prominent group in the department and felt isolated. It was stated by one faculty member:

I do not belong to any prevalent group in the department, it comprises of departmental head and his favored others ... that is why usually my colleagues have their gatherings and social plans together and I am not a part of them ... Usually, I feel neglected in conversations and my opinion for departmental issues as well as other matters is not sought or taken into account (P\#18).

Provocative victims indicated that department head favors certain groups based on his/her associations, and disregard of merit and similar practice is prevalent among colleagues. This promotes grouping in the department where members of one group ostracize others.

We are divided into groups, there is a dominant group that is favored by our department head and another group that has no such affiliation. The interpersonal interaction among the colleagues across groups is almost non-existent ... Even sometimes we ignore each other on purpose (P\#5).

\subsection{Perceived consequences of workplace ostracism for teaching faculty of HEIs}

This theme was further sub-divided in the following sub-themes.

4.4.1 Perceived consequences of workplace ostracism for provocative victims. The outcomes indicated by provocative victims included deviant behaviors (i.e. aggression toward the perpetrator, reduced task performance and interpersonal helping) and increased prohibitive voice.

The outcomes of provocative victims were mainly witnessed in the form of active behaviors such as complaining about the mistreatment and giving suggestions of inclusion, showing aggressive behavior toward the ostracized colleague and engaging in behaviors that are against the well-being of department and its stakeholders, such as leaving early, not completing the assigned tasks with due effort, intentionally showing slow progress and careless use of organizational resources. Some of them indicated that they do not help their colleagues and try to avoid giving favors for better functioning of the department. It was revealed by one of the faculty members:

Once my colleague was absent and the head of the examination asked me to perform duty in his place ... Although, I was free and could have helped in this regard, I refused (P\# 17).

Another faculty member stated:

I leave university as soon my classes are over and I do not complete my working hours ... If any extra work is assigned to me I usually refuse and even if I have to do it I just try to get rid of it by putting minimum efforts (P\#29).

The aggression of one participant was reflected through the following statement:

In this culture, there is no place for a person who shows compliance, here one has to speak up to survive and in certain cases, being rude is the only choice to retaliate against exclusion. I requested many times to also give me the membership in the departmental research committee as I also fulfill the qualifying criteria ... until I said them harshly my request was not considered (P\#5). 
While another faculty member showed indication of prohibitive voice as a reaction of being ostracized:

... I suggest my head to develop proper criteria so that everyone has an equal chance to be a part of departmental activities rather than favoring certain employees all the time... There should be some opportunities for formal and informal collaboration, maybe this helps to break the ice (P \#2).

Causes and consequences of workplace ostracism

4.4.2 Perceived consequences of workplace ostracism for submissive victims. It was indicated by submissive victims that they react to workplace ostracism through silence, increased work effort, interpersonal helping, negative gossip, knowledge hiding and displaced aggression.

Submissive victims showed some positive reactions as a response to workplace ostracism. These included improving their work performance and helping others. Few faculty members said:

I try to improve my lecture delivery and work for the departmental activities in an improved way, I hope it will improve my image and makes my colleagues and head realize my worth ( $\mathrm{P} \# 3$ ).

... I help my colleagues more, I offer them to share work if they are overburdened and help them in resolving issues ... Sometimes, I share teaching material and case studies, I think it will improve our relationships $(\mathrm{P} \# 12)$.

It was revealed that some of the submissive victims just chose to be silent and show no reaction:

I keep doing my work and refrain from raising voice against being ignored (P\#8).

Some negative outcomes were indicated such as:

I cannot openly confront my colleagues that ignore me, but I talk negatively about them with other faculty members and even sometimes with students ... at times I even exaggerate information about them to harm their reputation (P\#13).

In this institution, I feel left out and excluded, if I try to retaliate by aggression or by reducing my performance it generates further negative outcomes. If my colleague asks for some work-related information or something regarding research, I pretend not to possess it or I play dumb ( $\mathrm{P} \# 12)$.

Lastly, an indication of the aggressive reaction was also found among the submissive victims, but the difference was that it was not directly targeted toward those who ostracized them.

Being ostracized causes an intense surge of anger in me and I lash out at my friends or family members for no reason (P\#25).

4.4.3 Perceived consequences of workplace ostracism within the specific context of HEIs. On average, a mixed response regarding outcomes of workplace ostracism was obtained from both kinds of victim categories. Summing up, there was an overall trend of declining contextual performance in both kinds of victims, but reducing task performance was rarely traced (only in provocative victims). As one participant said,

I would never compromise on my assigned job duties, especially lecture delivery and research supervision ... However, I avoid any extra effort even if it is for the better functioning of the department (P\#26).

Some of the submissive victims indicated increasing tasks as well as contextual performance to improve their image and get included. Spillover impacts were also unique to submissive victims (i.e. in the form of displaced aggression).

Based on the findings of the present research, a conceptual model of the causes and consequences of workplace ostracism is proposed that shows the relative theme percentages (see Figure 1) that indicate the percentages in each box represent the relative occurrence of major concepts within each sub-theme. 
EJMBE 30,1

\section{8}

\section{Figure 1.}

Conceptual framework (the percentages in each box represent the relative occurrence of major concepts within each sub-theme)

\section{Causes of Workplace}

Ostracism
Consequences of Workplace

Ostracism

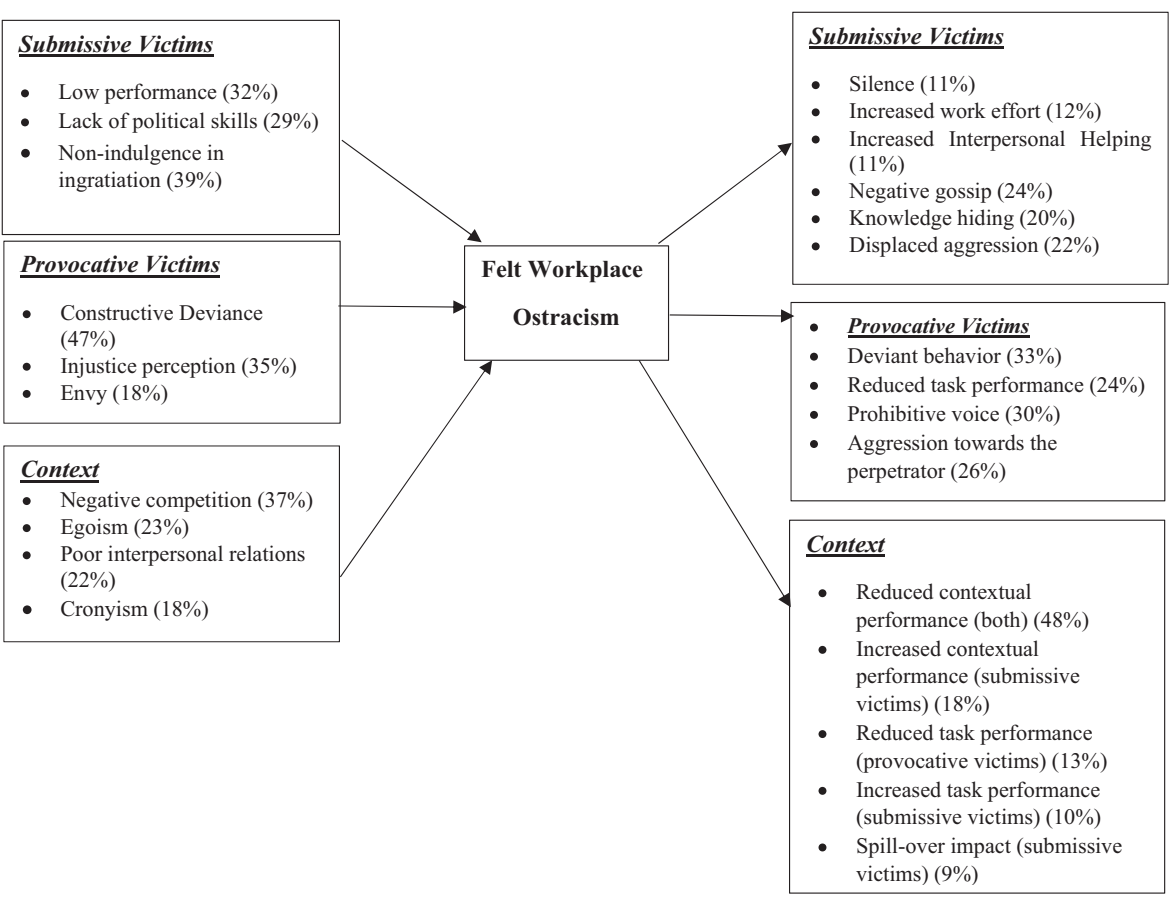

\section{Discussion}

The first theme was related to the perceived causes of workplace ostracism in HEIs. The provocative victims indicated that they felt ostracized because of being constructively deviant, which affirms the conception that personal behaviors of employees attract ostracism (Howard et al., 2019). In traditional work settings, departing from status quo is not liked, and an employee engaged in constructive deviance is perceived as disagreeable that increases the chances of being ostracized (Mao et al., 2018). Perceived injustice was deemed to be yet another reason for felt ostracism, and this makes sense because injustice offers a breeding ground for workplace mistreatments (Tepper et al., 2006). Lastly, provocative victims said that they faced ostracism from envied peers. The underlying cause is that excellent performance and possession of unique expertise also invites victimization from colleagues due to negative social comparison (Kim and Glomb, 2010; Mao et al., 2018).

Contrariwise, the submissive victims said their low performance makes them less socially desirable. This shows that low performance is not only an outcome of ostracism, but, in certain cases, it can be the cause of ostracism (Howard et al., 2019). Also, low political skills were found to be a cause of workplace ostracism. Employees who lack political skills are likely to be ostracized because they do not ingratiate, flatter or show compliance to others to become more sought after (Wu et al., 2019). The results affirm that submissive victims attribute the causes of mistreatments mainly to their characteristics and lower self-worth perceptions, whereas the provocative victims possess a better self-image and deem that mistreatment is always not the fault of the target (Cortina et al., 2018). 
Despite the nature of victims, contextual factors impacted all ostracized faculty members alike. It was revealed that certain cultural and organizational practices in HEIs promote ostracism. This signals toward the dysfunctional characteristics of HEIs in Pakistan that include negative competition, cronyism, poor interpersonal relations and egoism. Given limited resources and lack of merit-based practices, it is easy to gain personal benefits by ostracizing those employees who pose a threat. Self-interest and favoritism are deemed to be positively liked to workplace ostracism (Bilal et al., 2019). Organizations that do not encourage positive competition for the well-being of employees become home to mistreatment (Li et al., 2019). In case of unhealthy competition, instead of positively improving their work performance, employees try to create hurdles for others and do not refrain from showing hostile behaviors (George et al., 2012). Moreover, poor-quality interpersonal relationships result in negative outcomes such as ostracism (Chung, 2015). The indication of exclusionary climate in HEIs is given by Zimmerman et al. (2016), and thus it supports the results that lack of cohesive ties among employees reduces the social interaction and promotes exclusion in the workplace.

The results revealed that the reactions of provocative victims were more assertive and visible (Aquino and Lamertz, 2004). The most evident outcome of being ostracized was a reduction of contextual behaviors. Some victims indulged in prohibitive voice behaviors to raise their concerns about ostracism, while others showed aggression toward the employees who ostracize them. In contrast to prior evidence of negative relationship and voice behavior (Wu et al., 2019), a positive association was found. Employees use prohibitive voice to get protected from workplace threats such as workplace ostracism (Ma, 2016). It has been proved by past research that ostracism is a painful experience; victims can behave aggressively, and some victims have more potential of showing aggressive behavior than others (Ren et al., 2018). It was indicated by a few that they declined task performance following the episodes of ostracism, which is a common outcome of being ostracized (Robinson et al., 2013).

On the contrary, submissive victims had more positive or passive reactions. They engaged in improved work performance and helping behaviors that are a common tactic to becoming a more favorable individual to avoid victimization (Bilal et al., 2019). Besides, some of the victims in this category only remained silent, which is a unique outcome for the employees who have lower self-worth and self-esteem (Fatima et al., 2017). The negative outcomes shown by submissive victims were subtle like knowledge hiding and negative gossip to damage the reputation of the perpetrator. Some traits of employees make them reciprocate by hiding knowledge as a result of mistreatment (Arshad and Ismail, 2018), such as less extroversion exhibited by submissive victims elicits this response (Bosman, 2019; Demirkasimoglu, 2016). Negative gossip is also used as a way to convey undesirable work attitudes and is specifically targeted as a reaction of mistreatment (Ellwardt et al., 2012). Submissive victims lack courage and feared further ostracism; hence, they directed aggression toward others, that is, family and friends. The passive and insecure nature of submissive victims caused more positive, neutral or mildly negative reactions as compared to the confrontation from provocative victims (Aquino and Lamertz, 2004; Howard et al., 2019).

About the consequences of ostracism in the specific context of HEIs, it was affirmed that there was a lower tendency of reduced task performance (Bilal et al., 2019) that was only traced in provocative victims, while contextual performance was significantly reduced in both victim types (Fatima et al., 2019). Increased task and contextual performance were found only in submissive victims, while due to their non-willingness to defend mistreatment, the aggressive reaction is targeted toward others, showing spillover impact (Ren et al., 2018). This added to the emerging debate on mixed reactions of workplace ostracism in academic settings by clarifying which types of victims react in a prosocial manner and which react in an anti-social manner (Bilal et al., 2019).
Causes and consequences of workplace ostracism 
EJMBE 30,1

\section{Contributions to theory and practice}

This research has extended the work on specific causes and consequences of workplace ostracism in HEIs, building on the victimization framework as suggested by Howard et al. (2019). It has moved beyond the prior focus on outcomes of workplace ostracism in academic settings (Bilal et al., 2019; Fatima et al., 2017, 2019; Zimmerman et al., 2016), and has given a holistic view of factors that cause ostracism in HEIs and how they translate into employee outcomes. We have further highlighted how victim's characteristics and industry-specific factors shape unique antecedents and outcomes of ostracism, simplifying its sheer negative or positive outcomes or specific focus on certain personal or organizational predictors (Mao et al., 2018).

From a methodological viewpoint, we reaffirmed that qualitative inquiries yield useful insights in ostracism research because its perceptions and outcomes vary based on multiple personal and contextual factors (O'Reilly et al., 2014). The phenomenological approach is added to the extant empirical and narrowly focused investigations of ostracism in academia (Fatima et al., 2017; Nasir et al., 2017; Zimmerman et al., 2016).

From a practical perspective, HEIs should improve their work contexts to yield positive employee outcomes (Bilal et al., 2019). Efforts should be made for cooperative goal attainments, and unhealthy competition should be discouraged through accountability mechanisms. Formal and informal work gatherings should be initiated, such as meetings, seminars, workshops, trips and dinners, to bring faculty members closer and to discourage ostracism (Fiset et al., 2017). The university management in general, and department heads in specific, should take an active role in promoting merit-based practices to ensure all employees are included and fairly treated. Mentoring of perpetrators and victims could also help to reduce the incidents and outcomes of workplace ostracism. Diversity training and seminars should be carried out to promote their social interaction among faculty members. Faculty members should be positively reinforced for keeping organizational interest ahead of personal interest. The policies and grievance mechanisms should be put in place with specific regard to workplace ostracism so that the victims can report the exclusionary behavior confidentially. The faculty members themselves can take initiatives for collaborative working through positive emotional management, such as by avoiding envy, egoism and negative social comparison and by inculcating positive knowledge sharing and interpersonal helping (Bilal et al., 2017; Williams, 2009; Zhao et al., 2016).

\section{Limitations and future research directions}

This study has some of the inherent limitations of qualitative research such as small sample size, the possibility of respondent bias, hidden views, omission of information and limited applicability of research results. These shortcomings can be overcome by using triangulation and mixed-method approaches (Bryman and Bell, 2014). This study was limited to the causes and consequences of ostracism in HEIs; in future, more comprehensive understanding can be acquired by exploring the specific types of workplace ostracism in academia. Moreover, we focused on the nature of the victim and context, and in future, the characteristics of the perpetrator can also be used to examine the same phenomenon (Howard et al., 2019). We only explored one kind of workplace mistreatment; in future studies, other types of mistreatments such as incivility, discrimination and micro-aggression can be examined in HEIs (Schneider, et al., 2017). We only considered Pakistani HEIs; the same inquiry may yield contradictory findings in HEIs of other national and cultural contexts.

\section{Conclusion}

This study found that provocative and submissive victim status elicits different perceptions of causes of workplace ostracism in Pakistani HEIs and yields unique outcomes. The practices of 
cronyism, egoism, negative competition and poor interpersonal relations are inherent in Pakistani HEIs, fostering ostracism and causing varied outcomes such as reduced contextual performance (provocative and submissive victims), reduced task performance (provocative victims), spillover, and increased task and contextual performance (submissive victims).

\section{References}

Aquino, K. and Thau, S. (2009), "Workplace victimization: aggression from the target's perspective", Annual Review of Psychology, Vol. 60, pp. 717-741.

Aquino, K. and Lamertz, K. (2004), "A relational model of workplace victimization: social roles and patterns of victimization in dyadic relationships", Journal of Applied Psychology, Vol. 89 No. 6, pp. 1023-1034.

Arshad, R. and Ismail, I.R. (2018), "Workplace incivility and knowledge hiding behavior: does personality matter?", Journal of Organizational Effectiveness: People and Performance, Vol. 5 No. 3, pp. 278-288.

Banihani, M. and Syed, J. (2017), "Gendered work engagement: qualitative insights from Jordan”, The International Journal of Human Resource Management, Vol. 31 No. 5, pp. 1-27.

Bashir, I. and Khalil, U. (2017), "Instructional leadership at university level in Pakistan: a multi variable based comparative study of leadership styles of heads of academic departments", Bulletin of Education and Research, Vol. 39 No. 1, pp. 175-186.

Bilal, A.R., Fatima, T. and Akoorie, M. (2017), "Cronyism as a constraint in social capital development: investigating dark side of social relation", in Academy of Management Proceedings, 10510: Academy of Management, Briarcliff Manor, NY, Vol. 2017 No. 1, p. 10751.

Bilal, A.R., Fatima, T. and Imran, M.K. (2019), "Why ostracized full-time faculty should not be labeled as "low performer"? A qualitative insight from higher education in Pakistan", Journal of Applied Research in Higher Education, Advance online publication.

Bosman, T.M. (2019), The Relations of Personality, Conflict, and Future Interdependence with Knowledge Hiding Intentions, Master's Thesis, The University of Twente, Netherlands.

Braun, V. and Clarke, V. (2006), "Using thematic analysis in psychology", Qualitative Research in Psychology, Vol. 3 No. 2, pp. 77-101.

Bryman, A. and Bell, E. (2014), Research methodology: Business and management contexts, Oxford University Press, Southern Africa.

Chung, Y.W. (2015), "The mediating effects of organizational conflict on the relationships between workplace ostracism with in-role behavior and organizational citizenship behavior", International Journal of Conflict Management, Vol. 26 No. 4, pp. 366-385.

Cortina, L.M., Rabelo, V.C. and Holland, K.J. (2018), "Beyond blaming the victim: toward a more progressive understanding of workplace mistreatment", Industrial and Organizational Psychology, Vol. 11 No. 1, pp. 81-100.

Creswell, J. (2007), Qualitative Inquiry and Research Design: Choosing Among Five Approaches, 2nd ed., Sage Publications, Thousand Oaks, California, CA.

Demirkasimoglu, N. (2016), "Knowledge hiding in academia: is personality a key factor?", International Journal of Higher Education, Vol. 5 No. 1, pp. 128-140.

Ellwardt, L., Labianca, G.J. and Wittek, R. (2012), "Who are the objects of positive and negative gossip at work? A social network perspective on workplace gossip", Social Networks, Vol. 34 No. 2, pp. 193-205.

Fatima, T., Ilyas, M., Rehman, C.A. and Imran, M.K. (2017), "Empirical investigation of relationship between workplace ostracism and employee silence: a test of mediating effects of self-esteem and meaningful existence in context of public sector universities in Punjab", Abasyn Journal of Social Sciences, Vol. 10 No. 1, pp. 111-128. 
EJMBE 30,1

Follmer, E.H., Talbot, D.L., Kristof-Brown, A.L., Astrove, S.L. and Billsberry, J. (2018), "Resolution, relief, and resignation: a qualitative study of responses to misfit at work", Academy of Management Journal, Vol. 66 No. 2, pp. 440-465.

George, E., Chattopadhyay, P. and Zhang, L.L. (2012), "Helping hand or competition? The moderating influence of perceived upward mobility on the relationship between blended workgroups and employee attitudes and behaviors", Organization Science, Vol. 23 No. 2, pp. 355-372.

Halevy, N., Cohen, T.R., Chou, E.Y., Katz, J.J. and Panter, A.T. (2014), "Mental models at work: cognitive causes and consequences of conflict in organizations", Personality and Social Psychology Bulletin, Vol. 40 No. 1, pp. 92-110.

Hall, E., Chai, W. and Albrecht, J.A. (2016), "A qualitative phenomenological exploration of teachers' experience with nutrition education", American Journal of Health Education, Vol. 47 No. 3, pp. 136-148.

Hitlan, R.T. and Noel, J. (2009), "The influence of workplace exclusion and personality on counterproductive work behaviors: an interactionist perspective", European Journal of Work and Organizational Psychology, Vol. 18 No. 4, pp. 477-502.

Howard, M.C., Cogswell, J.E. and Smith, M.B. (2019), "The antecedents and outcomes of workplace ostracism: a meta-analysis", Journal of Applied Psychology, Advance online publication.

Jahanzeb, S. and Fatima, T. (2018), "How workplace ostracism influences interpersonal deviance: the mediating role of defensive silence and emotional exhaustion", Journal of Business and Psychology, Vol. 33 No. 6, pp. 779-791.

Jassim, G.A. and Whitford, D.L. (2014), "Understanding the experiences and quality of life issues of Bahraini women with breast cancer", Social science and Medicine, Vol. 107, pp. 189-195.

Kim, E. and Glomb, T.M. (2010), "Get smarty pants: cognitive ability, personality, and victimization", Journal of Applied Psychology, Vol. 95 No. 5, p. 889.

Leung, A.S., Wu, L.Z., Chen, Y.Y. and Young, M.N. (2011), "The impact of workplace ostracism in service organizations", International Journal of Hospitality Management, Vol. 30 No. 4, pp. 836-844.

Li, X., McAllister, D.J., Ilies, R. and Gloor, J.L. (2019), "Schadenfreude: a counternormative observer response to workplace mistreatment", Academy of Management Review, Vol. 44 No. 2, pp. 360-376.

$\mathrm{Ma}, \mathrm{C}$. (2016), "The role of approach and avoidance motivation in employee voice: the moderating effect of ostracism and contingent self-esteem", International Journal of Productivity and Performance Management, Vol. 65 No. 6, pp. 744-759.

Mao, Y., Liu, Y., Jiang, C. and Zhang, I.D. (2018), "Why am I ostracized and how would I react?-a review of workplace ostracism research", Asia Pacific Journal of Management, Vol. 35 No. 3, pp. 745-767.

Matthiesen, S.B. and Einarsen, S. (2015), "Perpetrators and targets of bullying at work: role stress and individual differences", Perspectives on Bullying: Research on Childhood, Workplace, and Cyberbullying, Vol. 22 No. 6, pp. 735-753.

Nasir, N., Khaliq, C.A. and Rehman, M. (2017), "An empirical study on the resilience of emotionally intelligent teachers to ostracism and counterproductive work behaviors in context of the higher educational sector of Pakistan”, Global Management Journal for Academic and Corporate Studies, Vol. 7 No. 1, pp. 130-139.

Ng, T.W. (2017), "Can idiosyncratic deals promote perceptions of competitive climate, felt ostracism, and turnover?", Journal of Vocational Behavior, Vol. 99, pp. 118-131. 
O'Reilly, J.A.N.E., Robinson, S.L. and Schabram, K. (2014), Handbook of Unethical Work Behavior: Implications for Individual Well-Being: Implications for Individual Well-Being, Routledge, United Kingdom.

Polit, D.F. and Beck, C.T. (2004), Nursing Research: Principles and Methods, Williams \& Wilkins, Lippincott.

Ren, D., Wesselmann, E.D. and Williams, K.D. (2018), "Hurt people hurt people: ostracism and aggression”, Current Opinion in Psychology, Vol. 19, pp. 34-38.

Richman, S.L. and Leary, M.R. (2009), "Reactions to discrimination, stigmatization, ostracism, and other forms of interpersonal rejection: a multimotive model", Psychological Review, Vol. 116 No. 2, pp. 365-383.

Robinson, S.L., O'Reilly, J. and Wang, W. (2013), "Invisible at work an integrated model of workplace ostracism”, Journal of Management, Vol. 39 No. 1, pp. 203-231.

Sarma, S.K. (2015), "Qualitative research: examining the misconceptions", South Asian Journal of Management, Vol. 22 No. 3, p. 176.

Saunders, B., Sim, J., Kingstone, T., Baker, S., Waterfield, J., Bartlam, B., Burroughs, H. and Jinks, C. (2018), "Saturation in qualitative research: exploring its conceptualization and operationalization", Quality and Quantity, Vol. 52 No. 4, pp. 1893-1907.

Schneider, K.T., Wesselmann, E.D. and DeSouza, E.R. (2017), "Confronting subtle workplace mistreatment: the importance of leaders as allies", Frontiers in Psychology, Vol. 8, p. 1051.

Scott, K.L. and Duffy, M.K. (2015), "Antecedents of workplace ostracism: new directions in research and intervention", Mistreatment in Organizations (Research in Occupational Stress and Well Being), Vol. 13, pp. 137-165.

Silverman, D. (2005), Doing Qualitative Research: A Practical Handbook, Sage, London.

Tepper, B.J., Duffy, M.K., Henle, C.A. and Lambert, L.S. (2006), "Procedural injustice, victim precipitation, and abusive supervision”, Personnel Psychology, Vol. 59 No. 1, pp. 101-123.

Waldeck, D. (2017), "Qualitative research with participants suffering from ostracism: a practical guide for the novice researcher", The Qualitative Report, Vol. 22 No. 7, pp. 1744-1758.

Waldeck, D., Tyndall, I. and Chmiel, N. (2015), "Resilience to ostracism: a qualitative inquiry", The Qualitative Report, Vol. 20 No. 10, pp. 1646-1670.

Williams, K.D. and Sommer, K.L. (1997), "Social ostracism by coworkers: does rejection lead to loafing or compensation?”, Personality and Social Psychology Bulletin, Vol. 23 No. 7, pp. 693-706.

Williams, K.D. (2007), "Ostracism: the kiss of social death”, Social and Personality Psychology Compass, Vol. 1 No. 1, pp. 236-247.

Williams, K.D. (2009), "Ostracism: a temporal need-threat model”, Advances in Experimental Social Psychology, Vol. 41, pp. 275-314.

Wu, W., Qu, Y., Zhang, Y., Hao, S., Tang, F., Zhao, N. and Si, H. (2019), "Needs frustration makes me silent: workplace ostracism and newcomers' voice behavior", Journal of Management and Organization, Vol. 25 No. 5, pp. 635-652.

Xu, E., Huang, X. and Robinson, S.L. (2017), "When self-view is at stake: responses to ostracism through the lens of self-verification theory", Journal of Management, Vol. 43 No. 7, pp. 2281-2302.

Yang, L.M. (2008), An Examination of Education Service Quality at Collegiate Physical Education Departments in Taiwan: Using a Gap Analysis Approach, Unpublished Ph.D. thesis, United States Sports Academy, Daphne, Alabama.

Zhao, H., Xia, Q., He, P., Sheard, G. and Wan, P. (2016), "Workplace ostracism and knowledge hiding in service organizations", International Journal of Hospitality Management, Vol. 59, pp. 84-94.

Zimmerman, C.A., Carter-Sowell, A.R. and Xu, X. (2016), "Examining workplace ostracism experiences in academia: understanding how differences in the faculty ranks influence inclusive climates on campus”, Frontiers in Psychology, Vol. 7, pp. 1-9. 
EJMBE

30,1

54

\section{Further reading}

Dahling, J.J. and Gutworth, M.B. (2017), "Loyal rebels? A test of the normative conflict model of constructive deviance”, Journal of Organizational Behavior, Vol. 38 No. 8, pp. 1167-1182.

\section{Corresponding author}

Ahmad Raza Bilal can be contacted at: abilal@su.edu.om

For instructions on how to order reprints of this article, please visit our website: www.emeraldgrouppublishing.com/licensing/reprints.htm Or contact us for further details: permissions@emeraldinsight.com 